\title{
Ácido linoléico conjugado: efeitos no perfil lipídico e na composição corporal de camundongos exercitados ${ }^{1}$
}

\author{
Silvio Anderson Toledo Fernandes ${ }^{1}$ \\ Antônio José Natali ${ }^{2}$ \\ Mateus Camaroti Laterza ${ }^{3}$ \\ Bruno Gonzaga Teodoro ${ }^{1}$ \\ Frederico Souzalima Caldoncelli Franco ${ }^{1}$ \\ Maria do Carmo Gouveia Peluzio ${ }^{4}$ \\ ${ }^{1}$ Instituto Federal do Sudeste de Minas Gerais, MG, Brasil \\ 2 Departamento de Educação Física da Universidade Federal de Viçosa, MG, Brasil \\ ${ }^{3}$ Faculdade de Educação Física e Desportos da Universidade Federal de Juiz de Fora, \\ MG, Brasil \\ ${ }^{4}$ Departamento de Nutrição e Saúde da Universidade Federal de Viçosa, MG, Brasil
}

\begin{abstract}
Resumo: Objetivo: Avaliar os efeitos do CLA associado à dieta hiperlipídica sobre o perfil lipídico e composição corporal de camundongos knockout para o gene da ApoE exercitados. Métodos: 32 camundongos foram divididos e submetidos à dieta normo e hiperlipídica suplementadas ou não com $1 \%$ de CLA. Todos realizaram exercício físico em esteira, durante 12 semanas. Utilizou-se o teste de KruskalWallis ao nível de significância de 5\%. Resultados: Os animais que ingeriram dieta hiperlipídica com CLA aumentaram o colesterol total e o LDL, comparado com os alimentados com dieta normolipídica associada ou não ao CLA. Observou-se aumento no ganho de peso dos camundongos que ingeriram dieta hiperlipídica com CLA, comparado com os normolipídicos suplementados com CLA. Conclusões: O CLA na concentração de 1\% não alterou nenhum dos parâmetros analisados, independente da dieta, e não foi protetor contra os efeitos da dieta hiperlipídica.
\end{abstract}

Palavras-chave: Aterosclerose. Lipídeos plasmáticos. Composição corporal. Exercício físico.

\section{Conjugated linoleic acid: effects on lipid profile and body composition of exercised mice}

Abstract: Objective: To evaluate the effects of CLA associated with high-fat diet on lipid profile and body composition of knockout mice for the ApoE gene exercised. Methods: A 32 mice were divided and submitted to a normal-fat diet and high-fat diet supplemented with 1\% CLA. All exercise training on a treadmill for 12 weeks. We used the Kruskal-Wallis test at a significance level of 5\%. Results: The animals fed high-fat diet with CLA increased total cholesterol and LDL, compared with those fed normal-fat diet associated or not with CLA. There was an increase in weight gain of mice who ate high-fat diet with CLA, compared with normal-fat supplemented with CLA. Conclusions: CLA at a concentration of $1 \%$ did not change any of the parameters analyzed, regardless of diet, and was not protective against the effects of high-fat diet

Keywords: Atherosclerosis. Serum lipids. Body composition. Physical exercise.

\section{Introdução}

O aumento da ingestão de alimentos com elevada densidade energética e elevado conteúdo de gordura associado à falta da prática de exercícios físicos, são características comuns do estilo de vida ocidental, o que pode levar ao desenvolvimento de doenças, tais como aterosclerose, obesidade, hipertensão, hiperlipidemias e outras (BHATTACHARYA et al., 2005). A aterosclerose tem sido a causa principal de doenças coronarianas, sendo causada por uma inflamação progressiva na parede dos vasos

\footnotetext{
${ }^{1}$ Derivado de dissertação de mestrado em Educação Física pela Universidade Federal de Viçosa, Minas Gerais.
}

sanguíneos pelo acúmulo de lipoproteínas de baixa densidade (LDL), em conseqüência do aumento do colesterol total no plasma. Este processo é devido a uma ativação endotelial, a partir da qual, ocorre um recrutamento de leucócitos e, com isso, inicia-se um centro de desenvolvimento e progressão de placas aterogênicas causando complicações clínicas (PETROVAN et al., 2007).

Ácido Linileico Conjugado (CLA) é a denominação dada a um grupo heterogêneo de ácidos graxos com 18 carbonos, com duas duplas ligações, formadas através de biohidrogenação e oxidação por processos naturais (BOCCA et al., 
2007). Na molécula não há nenhum grupo metileno separando as duplas ligações como ocorre nos ácidos linoleicos. Ao invés disso, há uma dupla ligação conjugada com configuração em cis (c) ou trans (t), onde, predominantemente, é apresentada nas posições $\mathrm{c} 9, \mathrm{t} 11$ e t10, c12 (BHATTACHARYA et al., 2006). Encontrado naturalmente em muitos produtos animais, o CLA é sintetizado por bactérias do rúmen, embora possa ser sintetizado em menor quantidade por animais não ruminantes (WHIGHAM et al., 2000). As principais fontes dietéticas de CLA são: carne bovina (3-4 mg/g), leite e manteiga $(5-7 \mathrm{mg} / \mathrm{g})$ e, em menor proporção, óleos de sementes de açafrão e girassol $(0,01$ a $0,12 \%$ dos ácidos graxos totais) (ALASNIER et al., 2002). O consumo de CLA tem demonstrado efeito positivo sobre o perfil lipídico e antiaterogênico em coelhos (KRITCHEVSKY et al., 2002) e sobre a composição corporal, com redução da massa gorda e aumento da massa magra, além da diminuição do ganho de peso em camundongos BALB/C machos (BHATTACHARYA et al., 2005).

O CLA tem sido usado como suplemento, pois eleva a atividade da lípase hormônio sensível e, conseqüentemente, da lipólise em adipócitos, elevando a oxidação de ácidos graxos, tanto no músculo esquelético quanto no tecido adiposo (PARK et al., 1997) em função da elevação dos ácidos graxos livres. É importante ressaltar ainda que alguns efeitos indesejáveis relacionados ao uso do ácido linoleico conjugado foram encontrados, tanto em estudos com humanos quanto em animais. Há relatos de aumento da resistência à insulina e aumento da glicose e insulina de jejum (SMEDMAN; VESSBY, 2001), elevação da peroxidação lipídica (RISERUS et al., 2001) e redução do HDL em humanos obesos tratados com CLA (STECK et al., 2007).

Exercícios físicos, com intensidade moderada, têm sido utilizados para prevenir ou reverter a formação de placas ateromatosas nas artérias, podendo alterar o perfil lipídico das lipoproteínas e diminuir o colesterol total (MEILHAC et al., 2001). Além disso, o exercício físico pode afetar a composição corporal, diminuindo a massa gorda e aumentando a massa magra (THOMSON et al., 2008). Entretanto, o impacto da prática habitual de atividade física no perfil lipídico e na composição corporal depende da qualidade da alimentação feita pelo indivíduo.
O acompanhamento de indivíduos praticantes de atividade física em academias tem demonstrado que o exercício físico tem sido uma estratégia para perda de peso e prevenção ou reversão da formação de placas ateromatosas nas artérias. Estes indivíduos também fazem uso de recursos ergogênicos, como o CLA, para maximizar a perda de peso, porém não atentam para o controle da dieta, consumindo muita gordura e excesso de calorias.

Como forma de constatar os efeitos de uma dieta rica em gordura e da efetividade do CLA nas doenças cardiovasculares, modelos animais, como camundongos knockout para o gene da apolipoproteina E (Apo E), apolipoproteina responsável pela remoção da lipoproteína de baixadensidade (LDL) no plasma, tem sido utilizados em estudos envolvendo a gênese da aterosclerose e das dislipidemias (COOPER et al. 2008). Estes camundongos e os seres humanos possuem, com poucas exceções, o mesmo conjunto de genes que controlam o metabolismo de lipoproteínas (HOFKER et al., 1998). Segundo Neuzil et al. (1998), existe uma semelhança entre a composição lipídica da lipoproteína de muito baixa intensidade (VLDL) extraída do plasma de camundongos deficientes do gene responsável pela expressão da Apo E, e a VLDL extraída do plasma de humanos com placas ateroscleróticas avançadas. Este fato reforça a validade do modelo de camundongos deficiente em Apo E para 0 estudo experimental de doenças coronarianas.

O propósito deste trabalho foi simular a condição de indivíduos que fazem exercício físico, mas consomem dieta rica em gordura e fazem suplementação com ácido linoléico conjugado. Desta forma, objetivou-se avaliar os efeitos do CLA associado à dieta hiperlipídica sobre as lipoproteínas plasmáticas e composição corporal de camundongos Apo E (-/-) exercitados.

\section{Métodos}

\section{Animais de Experimentação}

Foram utilizados 32 camundongos knockout para o gene que expressa a Apo E, com doze semanas de vida. Os animais foram divididos em quatro grupos: $\mathrm{N}$ (dieta normolipídica) $(\mathrm{n}=8), \mathrm{H}$ (dieta hiperlipídica) $(\mathrm{n}=8), \quad$ NCLA (dieta normolipídica com $1 \%$ de CLA) ( $n=8)$, e HCLA (dieta hiperlipídica com $1 \%$ de CLA) ( $n=8)$. Estes foram alocados em gaiolas coletivas de polipropileno e mantidos em ambiente com 
temperatura média de $21^{\circ} \mathrm{C} \pm 2 \stackrel{\circ}{ } \mathrm{C}$, com alternância de período de 12 horas claro/escuro. Todos receberam água e dieta ad libitum e fizeram corrida em esteira com intensidade moderada. O período do experimento foi de doze semanas e, antes da eutanásia, todos foram colocados em jejum por 12 horas.

Após a eutanásia com $\mathrm{CO}_{2}, 0$ sangue foi coletado por punção na região abdominal, sendo imediatamente centrifugado a $4000 \mathrm{rpm}$ por 15 minutos. O soro foi congelado e mantido em freezer a $-20^{\circ} \mathrm{C}$ até a análise. Todas as vísceras foram retiradas, separando a carcaça vazia (músculos e ossos) para as determinações de água, gordura e proteínas.

Os camundongos foram procedentes do Biotério Central do Centro de Ciências Biológicas e da Saúde, da Universidade Federal de Viçosa. Os procedimentos empregados no estudo foram aprovados pelo Comitê de Ética do Departamento de Veterinária desta universidade (processo nํ. 13/2008), estando de acordo com o Colégio Brasileiro de Experimentação Animal (COBEA).

Tabela 1. Composição das dietas experimentais ( $\mathrm{g} / \mathrm{kg}$ de dieta)

\begin{tabular}{|c|c|c|c|c|}
\hline Ingredientes & $\mathbf{N}$ & NCLA & $\mathbf{H}$ & HCLA \\
\hline Caseína & 140 & 140 & 200 & 200 \\
\hline Maltodextrina & 155 & 155 & - & - \\
\hline Sacarose & 100 & 100 & 500 & 500 \\
\hline Óleo de soja & 40 & 30 & 10 & - \\
\hline Celulose & 50 & 50 & 50 & 50 \\
\hline Mistura mineral & 35 & 35 & 50 & 50 \\
\hline $\begin{array}{l}\text { Mistura } \\
\text { vitamínica }\end{array}$ & 10 & 10 & 10 & 10 \\
\hline L-cistina & 1,8 & 1,8 & - & - \\
\hline $\begin{array}{l}\text { Bitartarato de } \\
\text { colina }\end{array}$ & 2,5 & 2,5 & 10 & 10 \\
\hline Colesterol & - & - & 10 & 10 \\
\hline $\begin{array}{l}\text { Gordura } \\
\text { hidrogenada }\end{array}$ & - & - & 150 & 150 \\
\hline Amido de milho & 465,692 & 465,692 & - & - \\
\hline CLA & - & 10 & - & 10 \\
\hline $\begin{array}{l}\text { Total } \\
\text { (cal/kg dieta) }\end{array}$ & 4002,8 & 4002,8 & 4530 & 4530 \\
\hline \multicolumn{5}{|c|}{$\begin{array}{l}\text { Legenda: N - dieta normolipídica sem CLA; NCLA - } \\
\text { dieta normolipídica com CLA; H - dieta hiperlipídica; } \\
\text { HECLA - dieta hiperlipídica com CLA. Grupo N e } \\
\text { NCLA (dieta preparada segundo AIN-93M, REEVES et } \\
\text { al., 1993); grupo H e HCLA (dieta preparada segundo a } \\
\text { A.O.A.C., 1989). }\end{array}$} \\
\hline
\end{tabular}

\section{Dietas, controle peso e ingestão alimentar}

A dieta hiperlipídica foi elaborada conforme Association of Official Analytical Chemistry A.O.A.C. (1989) e, a dieta normal, conforme AIN-
93M (REEVES et al., 1993), sendo elaboradas manualmente e mantidas congeladas e protegidas da luz até o momento da utilização. A concentração de CLA na dieta foi de $1 \%$ do total dessa. Substituiu-se dez (10) gramas de óleo de soja por dez gramas de CLA em cada quilo de dieta nas dietas dos grupos NCLA e HCLA (Tabela 1). O CLA utilizado apresentou $50 \%$ dos isômeros cis- -9 , trans- 11 e $50 \%$ dos isômeros trans- 10 , cis- 12 .

O peso corporal e a ingestão alimentar foram monitorados semanalmente para controle de peso e consumo de dieta.

\section{Protocolo de atividade física}

Todos os camundongos foram submetidos a um programa progressivo de corrida na esteira (INSITH $^{\circledR}$, Equipamentos Científicos, Ribeirão Preto - SP, Brasil), cinco dias por semana, 30 $\mathrm{min} / \mathrm{dia}$, a uma velocidade de 15 metros por minutos, por 12 semanas consecutivas (segundo MEILHAC et al., 2001). A progressão da carga do exercício está demonstrada na tabela 2.

Tabela 2. Programa de corrida utilizado no treinamento dos camundongos Apo $\mathrm{E}^{(--)}$

\begin{tabular}{cccc}
\hline Semanas & $\begin{array}{c}\text { Velocidade } \\
\text { (m/min) }\end{array}$ & $\begin{array}{c}\text { Tempo } \\
\text { (m/dia) }\end{array}$ & $\begin{array}{c}\text { Freqüência } \\
\text { (dias/semana) }\end{array}$ \\
\hline $\begin{array}{c}\text { 1 a } 2 \\
\text { (progressão } \\
\text { diária) } \\
\text { 3 a 12 }\end{array}$ & 10 a 15 & 10 a 30 & 5 \\
\hline
\end{tabular}

\section{Concentração de água, proteína e gordura corporal}

O percentual hídrico das carcaças dos animais foi avaliado pelo método gravimétrico com emprego de calor baseado na evaporação da água em estufa a $105^{\circ} \mathrm{C}$ por 24 horas. O percentual de gordura foi determinado pelo processo gravimétrico utilizando $o$ aparelho de Soxhlet usando-se éter etílico como solvente na extração por 8 horas. O percentual de proteína foi calculado pelo método primário de Kjeldahl, por meio da determinação do nitrogênio empregando o fator $\mathrm{N} x$ 6,25 (A.O.A.C., 1998).

\section{Concentração de Colesterol total, HDL e $L D L$}

As determinações de colesterol total, triglicerídeos (TG) e a lipoproteína de alta densidade (HDL) foram realizadas baseando-se no método enzimático colorimétrico, utilizando kit enzimático KATAL (FOSSATI; PRENCIPE 1982). A concentração de LDL no plasma foi calculada 
baseando-se na fórmula de Friedewald, citado por Warnick et al. (1990).

$$
\text { LDL = (colesterol total }-\mathrm{HDL})-(\mathrm{TG} \times \mathbf{0 , 2 0})
$$

\section{Análise estatística}

A análise dos dados foi realizada utilizando o software Sigma Statistic ${ }^{\circledR}$ for Windows, versão 3.0, sendo utilizado o teste não paramétrico de Kruskal-Wallis para grupos independentes. $O$ teste de Dunn's foi empregado para análise de múltipla comparação post-hoc, quando necessário. O nível de rejeição da hipótese de nulidade foi de $\mathrm{P}<0,05$ ou $5 \%$.

\section{Resultados}

\section{Colesterol total, $H D L$ e $L D L$}

Entre os grupos $\mathrm{H}$ e $\mathrm{N}$, não foi observado nenhuma diferença significativa nas lipoproteínas plasmáticas $(p>0,05)$. Contudo, entre os grupos HCLA e NCLA foram identificadas alterações estatisticamente significativas $(p<0,05)$ para 0 colesterol total e LDL. Pode-se verificar que os animais do grupo HCLA apresentaram maiores valores de colesterol total e LDL, quando comparado com os animais dos grupos NCLA. Os dados destas análises estão apresentados na Tabela3.

Tabela 3. Conteúdo de colesterol total, HDL e LDL nos camundongos ApoE ${ }^{(--)}$

\begin{tabular}{lccc}
\hline Grupos & Colesterol Total (mg/dL) & $\begin{array}{c}\text { HDL } \\
(\mathbf{m g} / \mathbf{d L})\end{array}$ & $\begin{array}{c}\text { LDL } \\
(\mathbf{m g} / \mathbf{d L})\end{array}$ \\
\hline $\mathrm{N}(\mathrm{n}=8)$ & 378 & 20,5 & 340,7 \\
& $(199,25-415)^{\mathrm{bc}}$ & $(16,25-29,75)^{\mathrm{a}}$ & $(157,45-387,5)^{\mathrm{bc}}$ \\
$\mathrm{H}(\mathrm{n}=8)$ & 775 & 13,75 & 755,5 \\
& $(737,5-975)^{\mathrm{ac}}$ & $(12,5-20)^{\mathrm{a}}$ & $(722,5-958)^{\mathrm{ac}}$ \\
$\mathrm{NCLA}(\mathrm{n}=8)$ & 399,5 & 25 & 350,7 \\
& $(371,5-445)^{\mathrm{bc}}$ & $(24,5-30)^{\mathrm{a}}$ & $(334-403,5)^{\mathrm{bc}}$ \\
HCLA (n=8) & 850 & 16,25 & 832,75 \\
\end{tabular}

Legenda: $\mathrm{N}$ - grupo com dieta normolipídica sem CLA; $\mathrm{H}$ - grupo com dieta hiperlipídica sem CLA; NCLA - grupo com dieta normolipídica e CLA; HCLA - grupo com dieta hiperlipídica e CLA. Dados: mediana (mínimo - máximo). Significância $(P<0,05)$ : valores com letras iguais na mesma coluna não apresentam diferença significativa $(P>0,05)$ ao teste de Dunn's.

Tabela 4. Peso corporal e ganho de peso dos camundongos Apo $\mathrm{E}^{(--)}$

\begin{tabular}{|c|c|c|c|}
\hline \multirow[b]{2}{*}{ Grupos } & \multicolumn{2}{|c|}{ Peso Corporal (g) } & \multirow{2}{*}{ Ganho de Peso (g) } \\
\hline & 1'a semana & $12^{a}$ semana & \\
\hline$N(n=8)$ & $\begin{array}{c}19,35 \\
(18,5-22,45)^{a}\end{array}$ & $\begin{array}{c}24 \\
(22,63-25,06)^{a}\end{array}$ & $\begin{array}{c}3,63 \\
(1,8-4,72)^{\text {ab }}\end{array}$ \\
\hline$H(n=8)$ & $\begin{array}{c}19,35 \\
(18,1-22,55)^{a}\end{array}$ & $\begin{array}{c}25 \\
(24,25-26,75)^{a}\end{array}$ & $\begin{array}{c}5 \\
(3,23-5,77)^{a b}\end{array}$ \\
\hline $\operatorname{NCLA}(n=8)$ & $\begin{array}{c}20,75 \\
(18-21,05)^{a}\end{array}$ & $\begin{array}{c}22,63 \\
(22-23,5)^{a}\end{array}$ & $\begin{array}{c}2,95 \\
(2,15-4)\end{array}$ \\
\hline $\operatorname{HCLA}(n=8)$ & $\begin{array}{c}19,65 \\
(19-20,85)^{a}\end{array}$ & $\begin{array}{c}25,15 \\
(23,22-28)^{a}\end{array}$ & $\begin{array}{c}5,5 \\
(4,25-6,75)^{a}\end{array}$ \\
\hline
\end{tabular}

Legenda: $\mathrm{N}$ - grupo com dieta normolipídica sem CLA; $\mathrm{H}$ - grupo com dieta hiperlipídica sem CLA; NCLA - grupo com dieta normolipídica e CLA; HCLA - grupo com dieta hiperlipídica e CLA. Dados: mediana (mínimo - máximo). Significância $(P<0,05)$ : valores com letras iguais na mesma coluna não apresentam diferença significativa $(P>0,05)$ ao teste de Dunn's.

\section{Peso Corporal (inicial e final) e Ganho de Peso.}

Não foi observada diferença estatística entre o peso corporal inicial e final dos animais nos grupos experimentais $(p>0,05)$ (Tabela 4). Todavia, os animais do grupo HCLA apresentaram maior ganho de peso, quando comparado com os camundongos do grupo NCLA. No entanto, os valores desse parâmetro não diferiram com os demais grupos (Tabela 4).

\section{Composição Corporal}

Não foi verificada diferença estatística para o peso da carcaça vazia e os respectivos valores percentuais de água, gordura, proteína e cinzas entre os grupos experimentais $(p>0,05)$ (Tabela $5)$. 
Tabela 5. Composição corporal dos camundongos Apo $\mathrm{E}^{(--)}$

\begin{tabular}{lccc}
\hline Grupos & $\begin{array}{c}\text { Água } \\
(\%)\end{array}$ & $\begin{array}{c}\text { Gordura } \\
(\%)\end{array}$ & $\begin{array}{c}\text { Proteínas } \\
(\%)\end{array}$ \\
\hline $\mathrm{N}$ & 64,64 & 5,66 & 18,64 \\
$(\mathrm{n}=8)$ & $(62,81-66,09)^{a}$ & $(4,78-7,14)^{a}$ & $(18,40-19,32)^{a}$ \\
$H$ & 65,56 & 5,04 & 19,68 \\
$(n=8)$ & $(64,65-66,59)^{a}$ & $(4,14-6,36)^{a}$ & $(18,60-19,91)^{a}$ \\
$N C L A$ & 64,2 & 5,84 & 20,60 \\
$(n=8)$ & $(62,77-64,93)^{a}$ & $(4,11-7,28)^{a}$ & $(18,95-21,2)^{a}$ \\
$H C L A$ & 66,34 & 4,22 & 20,35 \\
$(n=8)$ & $(65,71-66,75)^{a}$ & $(1,95-6,13)^{a}$ & $(19,38-21,09)^{a}$ \\
\hline
\end{tabular}

Legenda: $\mathrm{N}$ - grupo com dieta normolipídica sem CLA; $\mathrm{H}$ - grupo com dieta hiperlipídica sem CLA; NCLA - grupo com dieta normolipídica e CLA; HCLA - grupo com dieta hiperlipídica e CLA. Dados: mediana (mínimo - máximo). Significância $(P<0,05)$ : valores com letras iguais na mesma coluna não apresentam diferença significativa $(P>0,05)$ ao teste de Dunn's.

\section{Discussão}

No presente estudo todos os animais foram exercitados com o intuito de simular a condição de indivíduos que fazem atividade física, mas consomem dieta rica em gordura e fazem suplementação com ácido linoléico conjugado (CLA). Foi utilizada uma dieta hiperlipídica com $1 \%$ de colesterol e $15 \%$ de gordura hidrogenada, comparada com a normal, onde não se utiliza esses compostos. Já em relação ao suplemento, utilizou-se $1 \%$ de CLA sobre o consumo total da dieta (normal e hiperlipídica), com duração de 12 semanas. A discussão a respeito da dieta hiperlipídica é conclusiva no que diz respeito às alterações das lipoproteínas plasmáticas, peso e composição corporal, porém os questionamentos em relação à suplementação com CLA têm sido acirrados frente aos efeitos fisiológicos reportados por muitos grupos de pesquisa nos últimos anos. Os estudos que tratam da suplementação desse composto variam de 0,05 a $4 \%$ de CLA sobre 0 consumo total de dieta em animais (coelhos, ratos e camundongos), com tempo de experimentação variando de 2 a 12 semanas. O uso da dieta hiperlipídica com $1 \%$ de CLA foi em função da hipótese de que o CLA acrescido a dieta proporciona alterações na composição corporal e melhora no perfil lipídico do plasma.

Os dados do presente estudo mostram que a dieta hiperlipídica foi um fator prejudicial para os camundongos, pois quando esses exercitaram e consumiram dieta hiperlipídica, o exercício não foi um fator protetor, comparado com os que tiveram uma dieta normolipídica. Outro ponto que deve ser levado em consideração é a quantidade de caloria da dieta hiperlipídica, pois a maior concentração de colesterol total e LDL nos animais alimentados com essa dieta pode ser, também, devido à maior densidade calórica (Tabela 1).

A monitoração quanto à prática habitual de exercícios físicos tem recebido grande notoriedade no campo da saúde, não apenas por sua ação isolada na prevenção e no controle das doenças cardiovasculares (PAFFENBARGER et al., 2001), mas, também, por induzir alterações desejáveis nos níveis de lipídeos plasmáticos (MILLER; DUNSTAN, 2004). Entretanto, no presente estudo, pode-se deduzir que para se ter uma vida livre de doenças cardiovasculares, não basta só fazer exercícios físicos, a alimentação também deve ser um fator a ser observado, principalmente no que diz respeito à quantidade de gordura e caloria da dieta.

Em relação ao suplemento, o consumo de CLA não demonstrou efeito significativo no colesterol total e LDL. Entretanto, no estudo de Botelho et al. (2007), foi verificado diminuição do colesterol total quando os ratos foram suplementados com $4 \%$ de CLA na dieta, aumento do colesterol com suplementação de $1 \%$ de CLA e manutenção dos níveis de colesterol quando os animais foram suplementados com $2 \%$ de CLA, com um tempo de experimento de 21 dias. Nos trabalhos de Steck et al. (2007), com humanos obesos suplementados com 3,4 g/dia de CLA ou 6,4 g/dia de CLA, por 12 semanas consecutivas, não foram observados aumentos do LDL. Resultado semelhante foi apresentado por Raff et al. (2008) com humanos jovens suplementados com 5,5 g/dia de CLA por 5 semanas. Estes efeitos podem ser explicados 
pelo declínio da produção de colesterol, assim como de sua secreção pelo fígado ( $\underline{\text { SAKONO et }}$ al., 1999), e pela redução da síntese de triacilgliceróis, associada ao aumento de sua oxidação (RAHMAN et al., 2001).

Em relação ao aumento do ganho de peso, os animais alimentados com dieta hiperlipídica e suplementados com CLA demonstraram maiores valores comparado com os animais alimentados com dieta normolipídica e suplementado com CLA (Tabela 4). Frente a esses resultados, pode-se supor que a diferença na quantidade de calorias das duas dietas utilizadas, as quais apresentavam $4,0 \mathrm{Kcal} / \mathrm{g}$ (grupos NCLA) e $4,5 \mathrm{Kcal} / \mathrm{g}$ (grupos HCLA), foi suficiente para induzir aumento de peso nos animais do grupo HCLA. Os percentuais de gordura utilizados em relação ao valor calórico total das dietas, que foram de $4 \%$ na dieta normolipídica e $25 \%$ na dieta hiperlipídica, também apresentaram influência sobre o ganho de peso dos animais. (Tabela 1). Vale ressaltar que ambos os grupos fizeram exercício físico e foram suplementados com CLA, isto indica que a qualidade e quantidade de calorias da alimentação deve ser levada em consideração. Para efeito do CLA, não foram observados diferenças estatísticas no ganho de peso, quando comparado com os animais que não ingeriram CLA.

Sugere-se que, a quantidade de CLA utilizada não foi suficientemente adequada para alterar, significativamente, o ganho de peso dos animais suplementados. Mirand et al. (2004), trabalharam com ratos suplementados com $1 \%$ de CLA, por seis semanas e submetidos a exercício aeróbio em esteira e, também, não observaram diminuição do ganho de peso corporal em relação aos não suplementados sedentários. Da mesma forma, Steck et al. (2007), não encontraram diferenças significativas na perda de peso em humanos que ingeriram $3,4 \mathrm{~g}$ ou $6,4 \mathrm{~g}$ por dia de CLA por 12 semanas. Contudo, Hargrave et al. (2004) observaram diminuição do ganho de peso em camundongos suplementados com $1 \%$ de CLA, por um período de 14 dias, assim como Yang et al. (2003), em ratas ZDF suplementadas com $0,5 \%$ de CLA durante seis semanas.

Neste estudo, os animais que foram suplementados com $1 \%$ de CLA não demonstraram modificações nos percentuais de água, gordura, proteína e cinzas, quando comparados com os demais grupos. O possível mecanismo para explicar este resultado pode ser que $1 \%$ de CLA não é suficiente para alterar o metabolismo lipídico e, até mesmo protéico de camundongos com o gene deficiente para expressão da Apo E. Mirand et al. (2004), trabalharam com ratos Wistar adultos suplementados com $1 \%$ ou $2 \%$ de CLA combinado com atividade física moderada por seis semanas e, também, não verificarem diferenças significativas na composição corporal. Porém, resultados contrários aos nossos foram encontrados por Bhattacharya et al. (2005), quando estudaram camundongos BALB/C alimentados com dieta rica em gordura, suplementados com $0,4 \%$ de CLA e submetidos a exercício moderado em esteira, eles observaram diminuição de gordura e aumento de massa magra nos camundongos. Riserus et al. (2001), também encontraram resultados diferentes deste estudo quando trabalharam com humanos obesos que ingeriram 4,2 $\mathrm{g}$ de CLA/dia durante quatro semanas, estes indivíduos apresentaram uma diminuição do percentual de gordura.

Concluiu-se que, a dieta hiperlipídica é um fator prejudicial, pois mesmo suplementada com CLA aumentou o colesterol total, LDL e elevou o ganho de peso dos camundongos knockout para - gene da apoE exercitados. Os dados do presente estudo não possibilitam especificar os mecanismos responsáveis pela não alteração da composição corporal nos animais suplementados com CLA. Todavia, é possível que $1 \%$ de CLA não tenha alterado a atividade da lípase hormônio sensível, não aumentando o gasto energético, assim como, não alterando a atividade das enzimas carnitina palmitoil transferase e lipase lipoprotéica (GRANLUND et al., 2003). Sugere-se que novos trabalhos sejam feitos para analisar a atividade da lípase hormônio sensível e, conseqüentemente, da lipólise em adipócitos em um desenho experimentação como o deste trabalho.

\section{Referências}

ALASNIER, C.; BERDEAUX, O.; CHARDIGNY, J. M.; SEBEDIO, J. L. Fatty acid composition and conjugated linoleic acid content of different tissues in rats fed individual conjugated linoleic acid isomers given as triacylglycerols small star, filled. Journal of Nutrition Biochemistry, Stoneham, v. 3, n. 6, p. 337-345, 2002. 
ASSOCIATION OF OFFICIAL ANALYTICAL CHEMISTS. Official methods of analysis. 14 . ed. Washington: AOAC, 1989.

\section{ASSOCIATION OF OFFICIAL ANALYTICAL} CHEMISTS. Official methods of analysis. Washington: AOAC, 1998.

BHATTACHARYA, A.; BANU, J.; RAHMAN M.; CAUSEY, J.; FERNANDES, G. Biological effects of conjugated linoleic acids in health and disease. Journal of Nutrition Biochemistry, Stoneham, v. 17, n. 12, p. 789-810, 2006

BHATTACHARYA, A.; RAHMAN, M. M.; SUN, D.; LAWRENCE, R.; MEJIA, W.; McCARTER, R. The combination of dietary conjugated linoleic acid and treadmill exercise lowers gain in body fat mass and enhances lean body mass in high fat-fed male Balb/C mice. Journal of Nutrition, Philadelphia, v. 135, n. 5, p. 1124-1130, 2005.

BOCCA, C.; BOZZO, F.; GABRIEL, L.; MILIETTA, A. Conjugated linoleic acid inhibits Caco-2 cell growth via ERK-MAPK signaling pathway. Journal of Nutrition Biochemistry, Stoneham, v. 18, n. 5, p. 332-340, 2007.

BOTELHO, A. P.; SANTOS-ZAGO, L. F.; REIS, S. M. P. M.; OLIVEIRA, A. C. O efeito da suplementação com ácido linoléico conjugado sobre o perfil lipídico sérico em ratos. Revista Brasileira de Tecnologia Agroindustrial, Ponta Grossa, v. 1, n. 1, p. 1-7, 2007.

COOPER, M. H.; MILLER, J. R.; MITCHELL, P. L.; CURRIE, D. L.; McLEOD, R. S. Conjugated linoleico acid isomers no effect on atherosclerosis and adverse effects on lipoprotein and liver lipid metabolism in apoE ${ }^{-/}$mice fed a high-cholesterol diet. Atherosclerosis, Amsterdan, v. 200, n. 2, p. 294-302, 2008. Disponível em:

$<$ http://cat.inist.fr/?aModele=afficheN\&cpsidt=2079 7537>. Acesso em: 22 jan. 2011.

FOSSATI, P.; PRENCIPE, L. Serum triglycerides determined colorimetrically with an enzyme that produces hydrogen peroxide. Clinical Chemistry, Baltimore, v. 28, n. 10, p. 2077-2080, 1982.

GRANLUND, L.; JUVET, L. K.; PEDERSEN, J. I.; NEBB, H. I. Trans10, cis12-conjugated linoleic acid prevents triacylglycerol accumulation in adipocytes by acting as a PPARgamma modulator. Journal of Lipid Research, Memphis, v. 44, n. 8, p. 1441-1452, 2003.

HARGRAVE, K. M.; MEYER, B. J.; LI, C.; AZAIN, M. J.; BAILE, C. A.; MINER, J. L. Influence of dietary conjugated linoleic acid and fat source on body fat and apoptosis in mice. Obesity Research, Baton Rouge, v. 2, p. 1435-1444, 2004.
HOFKER, M. H.; VAN VLIJMEN, B. J.; HAVEKES, $\mathrm{L}$. M. Transgenic mouse models to study the role of APOE in hyperlipidemia and atherosclerosis. Atherosclerosis, Amsterdam, v. 137, n. 1, p. 111, 1998

KRITCHEVSKY, D. S. T.; TEPPER, S. A.; WRIGHT, S.; CZARNCHI, S. K. Influence of graded levels of conjugated linoleic acid (CLA) on experimental atherosclerosis in rabbits. Nutrition Research, Philadelphia, v. 22, p. 1275-1279, 2002.

MEILHAC, O.; RAMACHANDRAN, S.; CHIANG, K.; SANTANAM, N.; PARTHASARATHY, S. Role of arterial wall antioxidant defense in beneficial effects of exercise on atherosclerosis in mice. Arteriosclerosy, Thrombosy and Vascular Biology, Dallas, v. 21, n. 10, p. 1681-1688, 2001.

MILLER, Y. D.; DUNSTAN, D. W. The effectiveness of physical activity interventions for the treatment of overweight and obesity and type 2 diabetes. Journal of Science and Medicine in Sport, Belconnen, v. 7, n. 1, p. 52-59, 2004.

MIRAND, P. P.; ARNAL-BAGNARD, M. A.; MOSONI, L.; FAULCONNIER, Y.; CHARDIGNY, J. M.; CHILLIARD, Y. Cis-9, trans-11 and trans10 , cis-12 conjugated linoleic acid isomers do not modify body composition in adult sedentary or exercised rats. Journal of Nutrition, Philadelphia, v. 134, n. 9, p. 2263-2269, 2004.

NEUZIL, J.; CHRISTISON, J. K.; IHEANACHO, E.; FRAGONAS, J. C.; ZAMMIT, V.; HUNT, N. H. Radical-induced lipoprotein and plasma lipid oxidation in normal and apolipoprotein $E$ gene knockout (apoE-/-)mice: apoE-/- mouse as a model for testing the role of tocopherol-mediated peroxidation in atherogenesis. Journal of Lipid Research, Memphis, v. 39, n. 2, p. 354-368, 1998.

PAFFENBARGER JUNIOR, R. S.; BLAIR, S. N.; LEE, I. M. A history of physical activity, cardiovascular health and longevity: the scientific contributions of Jeremy N Morris, DSc. DPH, FRCP. International Journal of Epidemiology, Oxford, v. 30, p. 1184-1192, 2001.

PARK, Y.; ALBRIGHT, K. J.; LIU, W.; STORKSON, J. M.; COOK, M. E.; PARIZA, M. W. Effect of conjugated linoleic acid on body composition in mice. Lipids, Chicago, v. 32, n. 8, p. 853-858, 1997.

PETROVAN, R. J.; KAPLAN, C. D.; REISFELD, R. A, CURTISS, L. K. DNA vaccination against VEGF receptor 2 reduces atherosclerosis in LDL receptor-deficient mice. Arteriosclerosis, Thrombosis and Vascular Biology, Dallas, v. 27, n. 5, p. 1095-1100, 2007. 
RAFF, M.; THOLSTRUP, T.; BASU, S.; NONBOE, P.; SSRENSEN, M. T.; STRAARUP, E. M. A diet rich in conjugated linoleic acid and butter increases lipid peroxidation but does not affect atherosclerotic, inflammatory, or diabetic risk markers in healthy young men. Journal of Nutrition, Philadelphia, v. 138, n. 3, p. 509-514, 2008.

RAHMAN, S. M.; WANG, Y.; YOTSUMOTO, H.; CHA, J.; HAN, S.; IMOUE S. Effects of conjugated linoleic acid on serum leptin concentration, bodyfat accumulation, and beta-oxidation of fatty acid in OLETF rats. Nutrition, Burbank, v. 17, n. 5, p. 385-390, 2001.

REEVES, P. G.; NIELSEN, F. H.; FAHEY, G. C, Jr. AIN-93 purified diets for laboratory rodents: final report of the American Institute of Nutrition ad hoc writing committee on the reformulation of the AIN-76A rodent diet. Journal of Nutrition, Philadelphia, v. 23, n. 11, p. 1939-1951, 1993.

RISERUS, U.; BERGLUND, L.; VESSBY, B. Conjugated linoleic acid (CLA) reduced abdominal adipose tissue in obese middle-aged men with signs of the metabolic syndrome: a randomised controlled trial. International Journal of Obesity Related in Metabolism Disord, Hamshire, v. 25, n. 8, p. 1129-1135, 2001.

SAKONO, M.; MIYANAGA, F.; KAWAHARA, S.; YAMAUCHI, K.; FUKUDA, N.; WATANABE, K. Dietary conjugated linoleic acid reciprocally modifies ketogenesis and lipid secretion by the rat liver. Lipids, Chicago, v. 34, n. 9, p. 997-1000, 1999.

SMEDMAN, A.; VESSBY, B. Conjugated linoleic acid supplementation in humans--metabolic effects. Lipids, Chicago, v. 36, n. 8, p. 773-781, 2001.

STECK, S. E.; CHALECKI, A. M.; MILLER, P.; CONWAY, J.; AUSTIN, G. L.; HARDIN, J. W. Conjugated linoleic acid supplementation for twelve weeks increases lean body mass in obese humans. Journal of Nutrition, Philadelphia, v. 137, n. 5, p. 1188-1193, 2007.

THOMSON, R. L.; BUCKLEY, J. D.; NOAKES, M.; CLIFTON, P. M.; NORMAN, R. J.;

BRINKWORTH, G. D. The effect of a hypocaloric diet with and without exercise training on body composition, cardiometabolic risk profile, and reproductive function in overweight and obese women with polycystic ovary syndrome. Journal of Clinical and Metabolism, Palo Alto, v. 93, n. 9, p. 3373-3380, 2008.

YANG, M.; COOK, M. E. Dietary conjugated linoleic acid decreased cachexia, macrophage tumor necrosis factor-alpha production, and modifies splenocyte cytokines production. Experimental Biology Medicine, Maywood, v. 228, n. 1, p. 51-58, 2003.

WARNICK, G. R.; KNOPP, R. H.; FITZPATRICK, V.; BRANSON, L. Estimating low-density lipoprotein cholesterol by the Friedewald equation is adequate for classifying patients on the basis of nationally recommended cutpoints. Clinical

Chemistry, Baltimore, v. 36, n. 1, p. 15-19, 1990.

WHIGHAM, L. D.; COOK, M. E, ATKINSON, R. L. Conjugated linoleic acid: implications for human health. Pharmacology Research, Madison, v. 42, n. 6 , p. 503-510, 2000.

Endereço:

Silvio Anderson Toledo Fernandes

Rua Doutor Alvino de Paula, 95 Carlos Chagas Juiz de Fora MG Brasil

36081-280

Telefone: (32) 3217.7875 (32) 8859.8005

e-mail: silvio.fernandes@ifsudestemg.edu.br

Recebido em: 24 de março de 2010.

Aceito em: 5 de outubro de 2011.

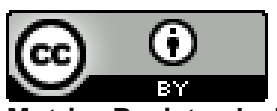

Motriz. Revista de Educação Física. UNESP, Rio Claro, SP, Brasil - elSSN: 1980-6574 - está licenciada sob Creative Commons - Atribuição 3.0 